\title{
Development of an Impairment-Based Individualized Treatment Workflow Using an iPad-Based Software Platform
}

\author{
Swathi Kiran, Ph.D., CCC-SLP, ${ }^{1}$ Carrie Des Roches, B.A., ${ }^{1}$ \\ Isabel Balachandran, B.A., ${ }^{1}$ and Elsa Ascenso, M.A. ${ }^{1}$
}

\section{ABSTRACT}

Individuals with language and cognitive deficits following brain damage likely require long-term rehabilitation. Consequently, it is a huge practical problem to provide the continued communication therapy that these individuals require. The present project describes the development of an impairment-based individualized treatment workflow using a software platform called Constant Therapy. This article is organized into two sections. We will first describe the general methods of the treatment workflow for patients involved in this study. There are four steps in this process: (1) the patient's impairment is assessed using standardized tests, (2) the patient is assigned a specific and individualized treatment plan, (3) the patient practices the therapy at home and at the clinic, and (4) the clinician and the patient can analyze the results of the patient's performance remotely and monitor and alter the treatment plan accordingly. The second section provides four case studies that provide a representative sample of participants progressing through their individualized treatment plan. The preliminary results of the patient treatment provide encouraging evidence for the feasibility of a rehabilitation program for individuals with brain damage based on the iPad (Apple Inc., Cupertino, CA).

KEYWORDS: iPad, constant therapy, individualized, rehabilitation

Learning Outcomes: As a result of this activity, the reader will be able to describe the various cognitive/ language operations involved in specific evidenced-based therapies, and explain the merits/disadvantages of targeted impairment-based rehabilitation for patients with language and cognitive deficits.

${ }^{1}$ Aphasia Research Laboratory, Boston University, Sargent College, Boston, Massachusetts.

Address for correspondence: Swathi Kiran, Ph.D., CCC-SLP, Speech Language and Hearing Sciences, Boston University Sargent College, 635 Commonwealth Ave., Boston, MA 02215 (e-mail: kirans@bu.edu).

iRehab: Incorporating iPads and Other Tablets in Aphasia Treatment; Guest Editor, Jacquie Kurland, Ph.D., CCC-SLP
Semin Speech Lang 2014;35:38-50. Copyright (C) 2014 by Thieme Medical Publishers, Inc., 333 Seventh Avenue, New York, NY 10001, USA. Tel: +1(212) 584-4662. DOI: http://dx.doi.org/10.1055/s-0033-1362995. ISSN 0734-0478.

License terms

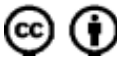


About 795,000 Americans each year suffer a new or recurrent stroke. ${ }^{1}$ Also, $\sim 1.7$ million individuals suffer from traumatic brain injury each year. ${ }^{2}$ Individuals with language and cognitive deficits following brain damage likely require long-term rehabilitation. Consequent$1 y$, it is a huge practical problem to provide the continued communication therapy that these individuals require.

\section{USING TECHNOLOGY TO IMPROVE TREATMENT DELIVERY}

There has been tremendous recent attention in research regarding the use and applicability of technology to improve treatment delivery. These range from implementing remote treatment delivery options to facilitate the provision of rehabilitation to individuals who cannot travel to obtain rehabilitation services to brain training software that individuals can use and interact with on a daily basis. Speech-language pathology rehabilitation, especially aphasia rehabilitation, is particularly suited for remote/telerehabilitation due to the emphasis on speech/visual and auditory communication. Recent studies have examined the efficacy of rehabilitation techniques such as videoconferencing for individuals with hearing, stuttering, and motor speech issues. ${ }^{3,4}$ Other studies have provided aphasia therapy over the Internet to individual patients. ${ }^{5,6}$ In a recent review, Van de Sandt-Koenderman identified the role of technology in the different domains of the International Classification of Functioning, Disability, and Health code that include alleviating impairment, facilitating functional communication, and social participation. ${ }^{7}$ She posits that technology will reshape the way clinicians are engaged in their patient's rehabilitation. Therefore, not only is there an increased awareness and momentum for applying computer technology in the rehabilitation of aphasia, there is increased patient demand to transition from traditional but outdated flash card-based therapy to keep up with the evolution of technology.

\section{WHAT IS THE EVIDENCE BEHIND USING TECHNOLOGY TO DELIVER TREATMENT?}

There have been several efforts to apply various forms of computer technology to rehabilitation of brain-injured patients. Given the focus of this special issue, we will limit our review of the evidence on the application of technology (available via Internet connection either on a computer or mobile application) for rehabilitation to language and communication deficits in the spirit of retraining disordered function, and hence we will refrain from discussion about alternative/augmentative technologies (and text-to-speech devices) that serve as communication aids. These include programs such as Lingraphica (Lingraphica Inc., Princeton, NJ) Sentence-Shaper (Psycholinguistic Technologies, Jenkintown, PA) and Touchspeak (Touchspeak ${ }^{\mathrm{TM}}$, London, England). Internet-based software treatments have been increasingly available for individuals with brain damage. For instance, a few studies have examined the effectiveness of CogMed (Pearson Company, Scandinavia, Sweden), a software targeted at improving working memory abilities in individuals with brain injury. ${ }^{8,9}$ These studies found improvements in working memory skills on the trained CogMed software as well as on other working memory tasks and functional settings. Likewise, Barnes et al examined the effectiveness of the software Posit Science (Posit Science, San Francisco, CA) in improving auditory processing speed in individuals with mild cognitive impairment (MCI). ${ }^{10}$ Although differences between the experimental and control groups were not statistically significant, verbal learning, and memory measures were higher in the experimental group than the control group. In another study, also examining cognitive training in MCI, Finn and $\mathrm{McD}$ Donald used Lumosity software (Lumos Lab, San Francisco, CA) to target attention, processing speed, visual memory in experimental and wait-listed controls. ${ }^{11}$ Results showed experimental participants improved on the training exercises more than the controls. Software solutions such as Lumosity and Posit Science provide a wide range of primarily cognitive therapy tasks that include attention, memory, and visuospatial processing, but they are not necessarily targeted toward individuals with brain damage. They appear to be geared more toward healthy older adults interested in delaying age-related cognitive decline. It should also be pointed out that these software platforms are primarily delivered on a computer (PC/MAC) over the Internet and are not specifically tabletbased delivery systems. 
There are other software solutions targeted specifically at aphasia therapy. Notwithstanding communication aids such as Sentence Shaper and Lingraphica, recent studies have demonstrated that use of "virtual speech therapists" in delivering remote language therapy to replace face-to-face patient-clinician sessions. Thus, Sentactics ${ }^{12}$ (Sentactics Corporation, Concord, CA) provides therapy for sentence production deficits and Oral Reading for Language in Aphasia with Virtual Therapist (ORLA$V T)^{13}$ provides oral reading practice for $\mathrm{pa}^{-}$ tients with aphasia. These technology-based rehabilitation solutions are limited in their functionality and range of available therapy tasks but provide a promising alternative to traditional flash card-based therapy.

\section{INDIVIDUALIZING REHABILITATION OPTIONS FOR PATIENTS}

A relatively unanswered question in most of the broad software platforms that are currently available is the nature and specificity of treatment provided. Given that all these software platforms can be used with non-brain-damaged individuals and brain-damaged individuals, is the treatment targeting a specific impairment that the patient exhibits or is it primarily a brain exercise? For both the software-based platforms and the virtual-therapist platforms, can therapy be individualized based on the patients' demographic profile and level of impairment severity? What are the pretreatment profiles of participants enrolled in treatment? How does performance improve, stabilize, or plateau as a function of this training? These issues are all very difficult to address as no two patients are alike in their demographic profile and, more importantly, no two patients are alike in their treatment outcomes. Nonetheless, the burden of evidence for technology-based treatment applications is no different than traditional treatment approach for rehabilitation after brain damage. Until we begin to address these questions, it is difficult to recommend technology-based applications for rehabilitation as replacements for traditional flash card-based therapy to improve clinical care for patients with brain damage.
In this article, we describe the development of an impairment-based, individualized treatment plan for patients that can be delivered through an iPad (Apple Inc., Cupertino, CA) software platform. Because of the flexibility that iPads provide to patients and the accessibility to free/paid apps that provide variable levels of exercises, it is important to standardize the nature and form of treatment that is provided to patients using iPads. Second, because patients have access to iPads at home, it provides a unique opportunity to examine the extent of compliance when patients are provided with a homework regimen, something that is very difficult to assess when providing traditional paper-and-pencil homework tasks. This article describes a portion of a broader project examining the effectiveness of specific impairmentbased treatments for patients with brain damage in which a large group $(n=55)$ patients entered into a prospective clinical efficacy study.

This article is organized into two sections. We will first describe the general methods of the treatment workflow for patients involved in this study. The second section provides four case studies that provide a representative sample of participants progressing through their individualized treatment plan. Because the therapy is delivered on an iPad, patients can either practice the therapy tasks assigned to them in the clinic or at home on a regular basis. Patient performance (both accuracy and latency) is analyzed on a periodic basis and patients progress to the next level of hierarchy after a certain level of performance criteria is met.

\section{METHODS}

\section{Treatment Workflow}

In this section, we describe the treatment workflow for each individual patient participating in our ongoing clinical efficacy study.

\section{ASSESSMENT OF PATIENT IMPAIRMENT}

Each patient is given a battery of standardized language tests, including the Revised-Western Aphasia Battery (R-WAB) ${ }^{14}$ to establish the type and severity of aphasia, the Boston Naming Test $(\mathrm{BNT})^{15}$ to determine confrontation naming ability, the Pyramids and Palm Trees ${ }^{16}$ 
to determine overall soundness of the semantic system, and the Cognitive Linguistic Quick Test $(\mathrm{CLQT})^{17}$ to determine the relative contribution of cognitive deficits such as attention and memory to language dysfunction and to rule out dementia. Based on the performance on each of these tests, a general profile is built for each patient based on whether they present with primary language deficits or primary cognitive deficits, and within each category, whether they present with low performance in that domain (more than half test scores in that domain are below 50\%) or high performance (more than half test scores in that domain are above 50\%). Clearly, patients present with a continuum of language/cognitive deficits, and therefore, generally, WAB Language Quotient (LQ), Aphasia Quotient (AQ), BNT, and Pyramids and Palm Trees (PPTT) tests are used to evaluate language skills and WAB Cortical Quotient (CQ) and Cognitive Linguistic Quick Test (CLQT) is used to evaluate cognitive skills. Performance on these tasks serve as a starting point for the therapy assignment; for instance, if a patient's letter discrimination score is $40 \%$ on $\mathrm{WAB}$, this patient would likely benefit from working on sound-to-letter matching exercises.

\section{ASSIGN INDIVIDUALIZED TASKS FOR EACH PATIENT}

The next step in the treatment workflow is to assign specific therapy tasks for each patient based on their relative language and cognitive profile. We implemented the Constant Therapy iOS platform (www.constanttherapy.com) to deliver the therapy. The choice of therapy tasks to be assigned came from a set of $30+$ therapy tasks broadly divided in language and cognitive therapy. Language therapy tasks were divided into (1) naming therapy: (a) rhyme judgment, (b) syllable identification, (c) phoneme-sound identification, (d) category matching, (e) feature matching, and (f) picture naming; (2) reading therapy: (a) spoken word-to-written word identification, (b) written word category identification, (c) reading passages, (d) long passage reading comprehension, and (e) reading maps, (3) writing therapy: (a) word copy completion, (b) word copy, (c) word spelling completion, (d) word spelling, (e) picture spelling completion, (f) picture spelling, (g) sound-to-letter match- ing, and (h) letter-to-sound matching; (4) sentence planning: (a) active sentence completion, (b) passive sentence completion. In addition, cognitive therapy tasks were divided into (1) visuospatial processing: (a) symbol cancellation, (b) telling time/analog clock; (2) memory: (a) visuospatial picture/word memory matching, (b) visuospatial auditory memory, and (c) voicemail task; (3) attention: (a) response inhibition, (b) symbol cancellation; (4) problem solving: (a) analytical reasoning with subtasks such as (i) alphabetical word ordering, (ii) alphabetical picture ordering; (b) arithmetic with subtasks such as (i) addition, (ii) multiplication, (iii) subtraction, and (iv) division; and (c) quantitative reasoning with subtasks such as (i) time estimation task, (ii) word math problems; (5) executive function: (a) sequencing a set of steps/ instructions. Details regarding the development of the stimuli for each of these tasks are not provided here due to space limitations. The range of therapy tasks, their scientific and clinical rationale, and specific evidence regarding their efficacy are provided in Appendix 1.

The general procedures for assignment of treatment were as follows. During the initial session, a subset of potential therapy tasks was assigned as baselines. As long as performance on a task was below $80 \%$ accuracy, that task was assigned for therapy. Because we examined both accuracy and latency as our dependent measures, we chose $80 \%$ accuracy as a cutoff to allow for examination of a maximum of $20 \%$ change in accuracy and corresponding decreases in latencies. If a patient performed higher than $80 \%$ on a particular task, the next level of difficulty of that task was assigned to the patient, or a different task examining the same skill (e.g., rhyming instead of sound identification) was assigned to the patient. For each patient, five to six tasks with up to 10 items in each task were assigned as that week's "therapy schedule." Participants were incrementally assigned tasks during the course of the 10week treatment program. Therefore, each patient was provided with an individualized treatment plan, which was modified frequently during the course of their participation in the study.

Participant Action at Home/Clinic Participants were provided with usernames and passwords to $\log$ into the Constant Therapy app and 
were then asked to practice the therapy up to 6 days a week for 1 hour each week. Participants were assured that there was no penalty whether they did or did not $\log$ in every day and complete the therapy, but that their therapy practice time would be recorded by the software. Participants were seen in the clinic on a weekly basis to review and monitor progress.

Analysis of Patient Performance and Progress One of the key aspects of the software platform is that the clinician can remotely analyze each patient's progress from his or her clinician account. During the weekly clinic sessions, the clinician would decide to continue the participant on the same task or to modify the treatment plan based on the patient's performance. If the participant achieved $95 \%$ or higher accuracy two times in succession, the clinician would either progress the next level of difficulty (e.g., addition level 1 to addition level 2) or would progress to a different task (e.g., assign category identification after category matching). If participants performed at low accuracies ( $40 \%$ or lower) over several sessions, that therapy task was replaced with another task from the task list. Data for each patient's accuracy and latency were plotted over for every session they performed the therapy task for every week up to 10 weeks. Fig. 1 shows a representative sample of participant 84's overall treatment plan in a snapshot, indicating how therapy tasks were assigned during the period of treatment and the overall accuracy for that task each session. As can be seen, therapy tasks are introduced and removed from the patient's therapy schedule based on performance. In addition, for each patient, for each treatment task, a trend line was computed on the time series data and the coefficient of determination $\left(R^{2}\right)$ was
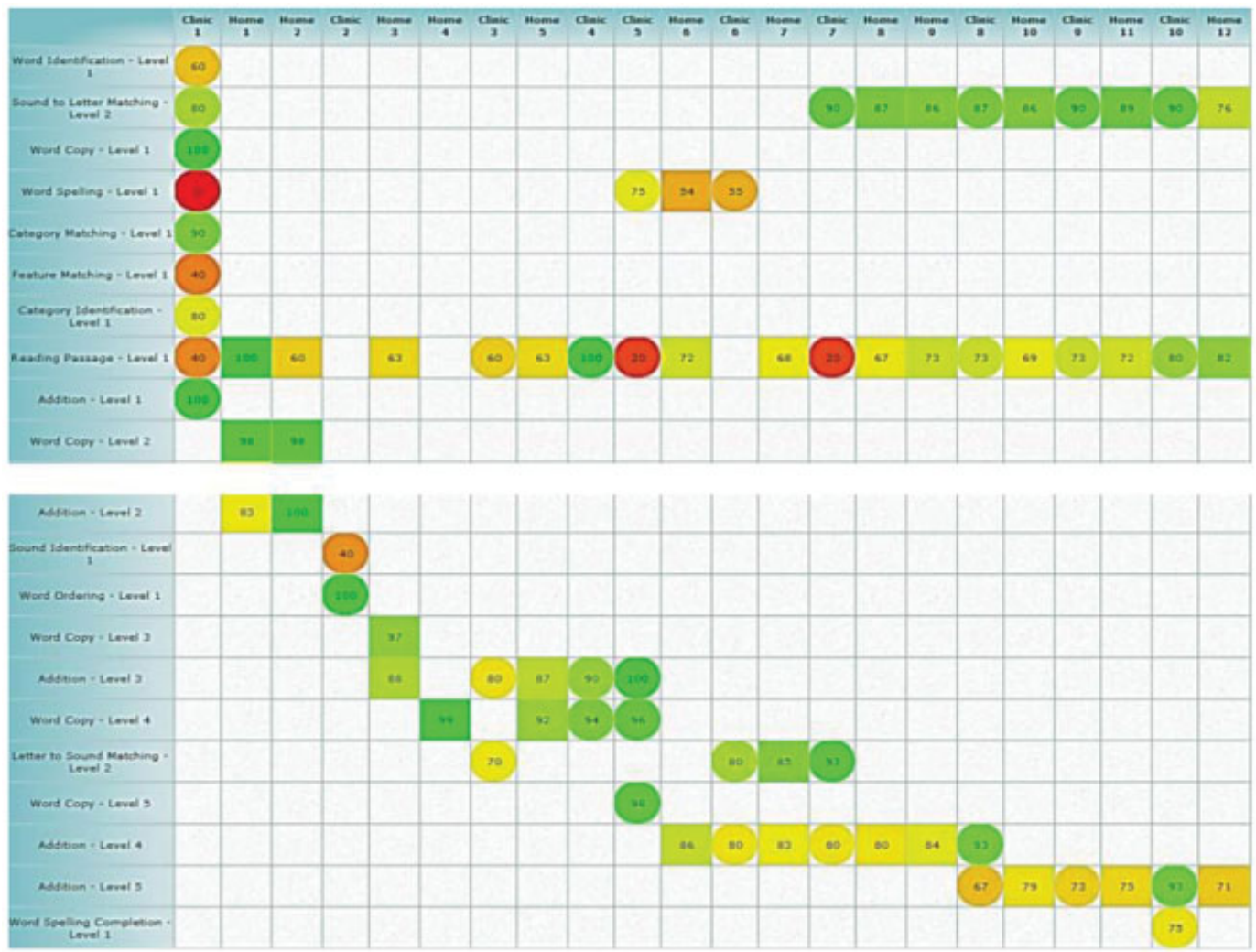

Figure 1 Overall performance of patient 84 on accuracy for all the therapy tasks assigned. The $x$-axis indicates the schedule for each week and whether the session was at home or in the clinic. The $y$-axis indicates all the therapy tasks assigned. Cells indicate the patient accuracy (e.g., 89\%) and cell colors indicate the population mean: green indicate patient performance is above the population mean, red, yellow and orange indicate the patient performance in below the population mean. 
Table 1 Standardized Test Performance for Four Patients, Pre- and Posttreatment

\begin{tabular}{|c|c|c|c|c|c|c|c|c|c|}
\hline & \multirow[b]{2}{*}{$n$} & \multicolumn{2}{|c|}{ Patient 84} & \multicolumn{2}{|c|}{ Patient 108} & \multicolumn{2}{|c|}{ Patient 25} & \multicolumn{2}{|c|}{ Patient 05} \\
\hline & & $\overline{\text { Pre (\%) }}$ & Post (\%) & $\overline{\text { Pre }(\%)}$ & Post (\%) & $\overline{\text { Pre (\%) }}$ & Post (\%) & Pre (\%) & Post (\%) \\
\hline Fluency total & 20 & 45.00 & 75.00 & 95.00 & 100.00 & 60.00 & 65.00 & 95.00 & 95.00 \\
\hline Auditory comprehension total & 200 & 53.00 & 69.00 & 96.50 & 93.00 & 66.50 & 79.50 & 98.00 & 94.00 \\
\hline Repetition total & 100 & 84.00 & 85.00 & 92.00 & 96.00 & 66.00 & 75.00 & 92.00 & 94.00 \\
\hline Naming and word finding total & 100 & 24.00 & 34.00 & 90.00 & 93.00 & 63.00 & 58.00 & 85.00 & 93.00 \\
\hline Reading total & 100 & 13.00 & 33.33 & 84.00 & 84.00 & 52.00 & 52.00 & 86.0 & 84.0 \\
\hline Writing total & 100 & 25.00 & 42.50 & 73.00 & 89.00 & 34.5 & 37.5 & 46.0 & 74.0 \\
\hline Apraxia & 60 & 90.00 & 98.33 & 98.33 & 100.00 & 95.00 & 88.33 & 98.33 & 100.00 \\
\hline $\begin{array}{l}\text { Constructional, visuospatial } \\
\text { total }\end{array}$ & 100 & 18.50 & 42.00 & 53.00 & 62.00 & 69.00 & 65.00 & 84.00 & 91.00 \\
\hline WAB Language Quotient & & 38 & 50.12 & 90.3 & 92.1 & 61.9 & 66.5 & 86.8 & 89.7 \\
\hline WAB Cortical Quotient & & 45.05 & 61.58 & 88.53 & 91 & 66.45 & 69.68 & 89.78 & 92.35 \\
\hline WAB Aphasia Quotient & & 50.2 & 67.6 & 93.7 & 96.4 & 63.2 & 68.5 & 93 & 94.2 \\
\hline Cognitive Linguistic & & & & & & & & & \\
\hline Quick Test & & & & & & & & & \\
\hline Attention & 215 & 8.84 & 36.28 & 33.49 & 45.58 & 78.60 & 79.07 & 87.44 & 92.56 \\
\hline Memory & 185 & 57.84 & 64.86 & 68.65 & 80.00 & 45.41 & 54.05 & 83.24 & 87.57 \\
\hline Executive functions & 40 & 7.50 & 15.00 & 25.00 & 27.50 & 47.50 & 55.00 & 65.00 & 70.00 \\
\hline Language & 37 & 40.54 & 43.24 & 72.97 & 78.38 & 40.54 & 45.95 & 67.57 & 78.38 \\
\hline Visuospatial skills & 105 & 16.19 & 28.57 & 31.43 & 37.14 & 74.29 & 80.95 & 85.71 & 91.43 \\
\hline Composite severity & 20 & 25.00 & 35.00 & 60.00 & 75.00 & 75.00 & 80.00 & 90.00 & 100.00 \\
\hline Clock drawing & 13 & 0.00 & 0.00 & 61.54 & 76.92 & 46.15 & 61.54 & 100.00 & 92.31 \\
\hline Boston Naming Test & 60 & 0.00 & 3.33 & 93.33 & 95.00 & 13.33 & 36.67 & 73.33 & 80.00 \\
\hline Pyramids and Palm Trees test & 52 & 63.46 & 65.38 & 82.69 & 90.38 & 78.85 & 78.85 & 96.15 & 98.08 \\
\hline
\end{tabular}

Results are provided for the WAB, Cognitive Linguistic Quick Test, Boston Naming Test, and Pyramids and Palm Trees test. Test scores are provided for the total number of items. See text for details. Abbreviation: WAB, Western Aphasia Battery.

computed. $R^{2}>0.2$ indicated a linear trend in data (for both accuracy and latency).

\section{Case Studies Implementing This Treatment Workflow}

In this section, we review four cases from our ongoing data collection efforts.

\section{EXAMPLE 1: LOW LANGUAGE PROFILE, LOW COGNITIVE PROFILE}

The first patient, No. 84, is a 66-year-old man who suffered a stroke $\sim 14$ months prior to participation in this study. This participant presented with low performance on both language and cognitive measures. Therefore, as seen in Table 1, this participant's LQ was 38 and $A Q$ was 50.2. This participant also presented with a low CQ (45.05) and generally low scores on all aspects of cognitive processing including atten- tion, memory, executive functions, and visuospatial processing on the CLQT. Oral naming was severely impaired. This patient was assigned the following tasks in treatment: category matching, feature matching, picture naming, rhyming, sound identification, word identification, sound-to-letter matching, and word copy to work on various aspects of naming, reading, and writing within language processing; and picture matching and symbol cancellation to work on attention, memory, and visuospatial aspects of cognitive processing. Note that these tasks were assigned to this participant over the course of the 10-week period, and for some tasks, such as symbol matching and word copy, the patient progressed to the next level. Fig. 2A shows a representative sample of this participant's progression through word copy (level 2) where improvements in accuracy are accompanied by increased latency on the task. This patient 

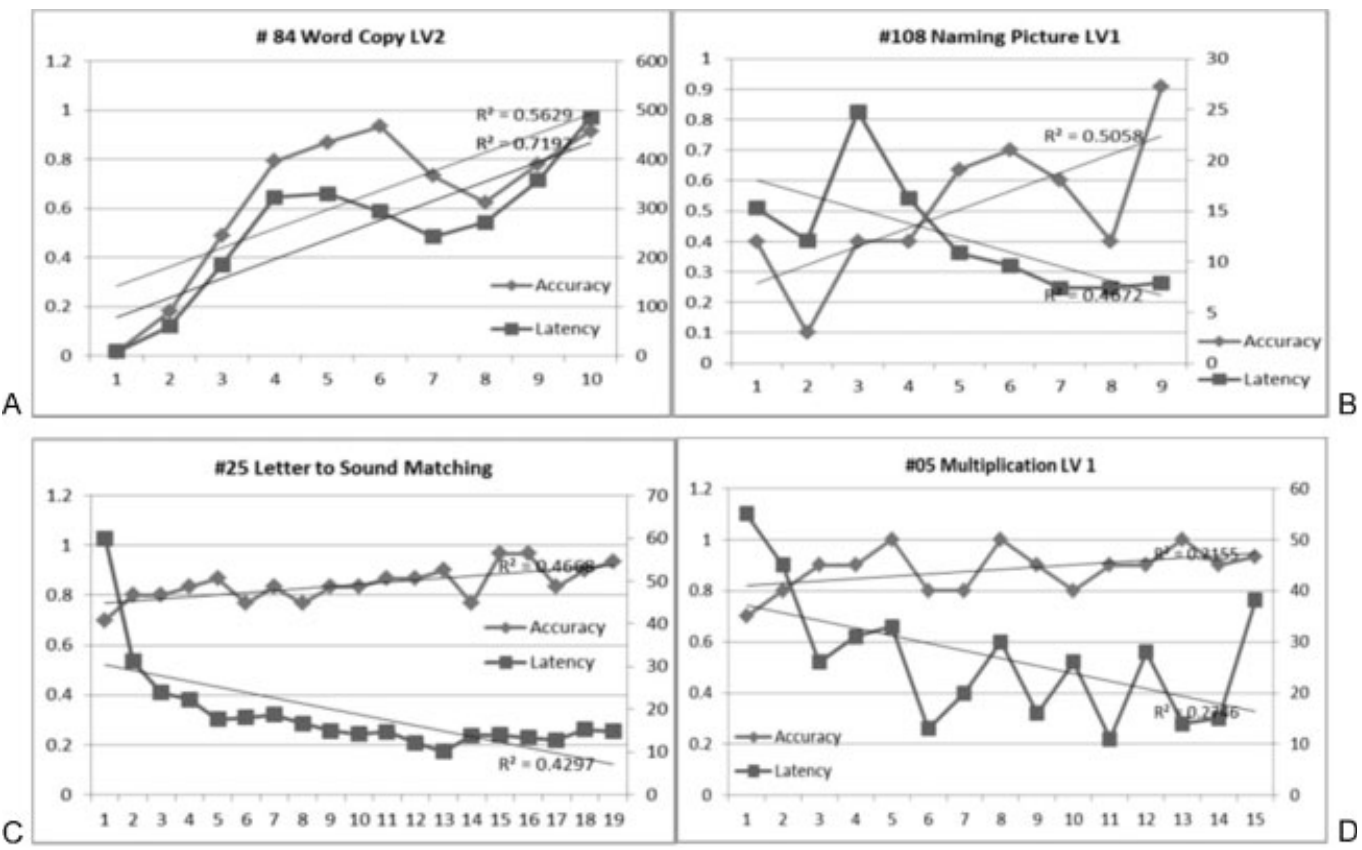

Figure 2 (A) Performance on accuracy and latency for patient 84 on one task: word copy level 2; (B) performance on accuracy and latency for patient 108 on one task: naming pictures; (C) performance on accuracy and latency for patient 25 on one task: letter-to-sound matching; and (D) performance on accuracy and latency for patient 05 on one task: multiplication level 1. For all graphs, accuracy is indicated on the left $y$-axis, latency is indicated on the right $y$-axis. the $x$-axis indicates number of sessions the task was completed. Linear slopes and $R^{2}$ values are plotted for accuracy and latency.

completed 48 therapy sessions (i.e., logged in to complete the therapy assignment) over the course of 10 weeks. At the end of treatment, this participant was tested on all the standardized measures and showed improvements in LQ (38 to 50.1) CQ (45.0 to 61.5), AQ (50.2 to 67.6), as well as improvements on all subtests of CLQT including attention (8 to $36.2 \%)$, memory (57.8 to $64.8 \%)$, executive function (EF) (7.5 to $15 \%)$, visuospatial skills (16.1 to $28.5 \%)$ and on the BNT (0\% to $3 \%)$.

\section{EXAMPLE 2: HIGH LANGUAGE PROFILE, LOW COGNITIVE PROFILE}

The next patient, No. 108, was a 75-year-old man who suffered a stroke 29 months prior to participation in this study. This participant presented with high performance on language subtests but low performance on cognitive measures. That is, this participant's LQ was 90.3 and AQ was 93.7. Patient 108 presented with a lower CQ (88.5) and generally low scores on attention, executive functions, and visuospa- tial processing on the CLQT. This patient was assigned the following tasks in treatment: picture spelling and picture naming to address language processing and clock reading and instruction sequencing, picture ordering, sound matching, symbol matching, voicemail to address attention, visuospatial processing, and executive function deficits. Note that these tasks were assigned to this participant over the course of the 10-week period, and he progressed multiple levels of difficulty on picture spelling (levels 1 to 3 ) and symbol matching (levels 1 to 2). Fig. 2B shows a representative sample of this participant's progression on a picture naming task. ${ }^{*}$ As accuracy on the task improved over the course of 11 weeks, latency also decreased. At the end of treatment, this participant was tested on all the standardized measures and showed improvements in LQ

\footnotetext{
* We should point out that patient 108 served as a control in this study, hence he did not complete treatment sessions at home and was seen weekly once by the clinician for 10 weeks.
} 
(90.1 to 92.1) CQ (88.5 to 91), AQ (93.7 to 96.4), as well as improvements on all subtests of CLQT including attention (33.4 to $45.58 \%$ ), memory (68.6 to $80.0 \%$ ), EF (25 to $27.5 \%$ ), visuospatial skills (31.4 to $37.14 \%$ ) and on clock drawing (61.5 to $76.9 \%)$.

\section{EXAMPLE 3: LOW LANGUAGE PROFILE, HIGH COGNITIVE PROFILE}

Our third patient, No. 25, is a 77-year-old man, who suffered a stroke 168 months and a secondary traumatic brain injury $\sim 60$ months prior to participation in the study. Based on standardized tests, this participant presented with low performance on language subtests but relatively higher performance on cognitive measures. That is, this participants' LQ was 61.9, CQwas 66.4, and AQwas 63.2. This participant presented with moderate scores on memory and language subtests on the CLQT and was within normal limits for performance on attention, EF, and visuospatial skills. This patient was assigned the following tasks in treatment: category identification, category matching, feature matching, letter-to-sound matching, reading passage, sound identification, sound-to-letter matching, word copy, and word spelling to address language processing and addition and word ordering to address working memory. Over the 10 weeks of the study, this patient completed 73 sessions (i.e., logged in to complete the therapy assignment). During this period, the patient progressed to the next levels for several tasks including such as addition (level 1 to 5), word copy (level 1 to 5). Fig. $2 \mathrm{C}$ shows a representative sample of this participant's progression through letter-tosound matching; as accuracy on the task improved, latency also decreased. At the end of treatment, this participant was tested on all the standardized measures and showed improvements on the LQ (61.9 to $66.5 \%)$ CQ (66.4 to 69.6\%), AQ (63.2 to 68.5), as well as improvements on all subtests of CLQT.

\section{EXAMPLE 4: HIGH LANGUAGE PROFILE- HIGH COGNITIVE PROFILE}

Patient 05 was a 56-year-old man who suffered a stroke 147 months prior to his participation in the study. This participant presented with high language and cognitive skills, based on stan- dardized tests. Thus, this participants' LQ was 86.8, CQ was 89.7, and AQ was 93. This participant shows high performance on all subtests of the CLQT including attention, memory, EF, and visuospatial skills. This patient was assigned the following tasks in treatment: category matching, feature matching, letter-to-sound matching, sound-to-letter matching, map reading, picture spelling, reading passage, rhyming, sound identification, syllable identification, word spelling to address language processing and addition, subtraction, multiplication, division, picture ordering, word ordering, and word problems to address cognitive processing. During the course of 10 weeks, this participant completed 89 therapy sessions. Again, this patient progressed through several levels for various tasks including addition (level 1 to 4 ), map reading (level 1 to 3 ), multiplication (level 1 to 2), picture spelling (level 1 to 3 ), subtraction (level 1 to 2), word spelling (level 1 to 5) during the course of treatment. Fig. 2D shows a representative sample of this participant's progression through multiplication level 1. At the end of treatment, this participant was tested on all the standardized measures and showed improvements on the LQ (86.8 to 89.7), CQ (89.7 to 92.3), AQ (93 to 94.2, BNT (73 to $80 \%$ ), as well as improvements on all subtests of CLQT with the exception of clock drawing.

\section{DISCUSSION}

The present study was aimed at developing an impairment-based, individualized treatment plan for patients that can be delivered through an iPad. Using research evidence published for rehabilitation of various aspects of brain damage, we first developed a series of tasks targeted at addressing specific aspects of language and cognitive processing. These tasks were implemented into a software platform (Constant Therapy) to provide individualized therapy for individual patients enrolled in the study. The four case studies described describe how therapy can be targeted for an individual with low cognitive and language performance, high language and low cognitive performance, high cognitive and low language performance, and high language and cognitive performance. 
These examples are simply four benchmarks; however, most patients obviously fall somewhere along these two dimensions. Importantly, the range of tasks described in this article illustrates the breadth of impairment-based language and cognitive rehabilitation that can be provided to patients.

Preliminary results from four patients provide some interesting observations. First, all participants improved in their iPad-based therapy tasks in general, both terms of accuracy and well as latency on the tasks (however, see exception about patient 84 who increased in his latency). A complete description of the progression of each therapy task for each patient is out of the scope of this article; however, all participants had at least one or two tasks that they did not improve during the course of the study. Nonetheless, participants showed changes on standardized tests, although the amount of change was variable: patient 84 showed improvements on both language and cognitive measures, patient 108 showed more improvements on cognitive measures, patient 25 did not show much improvement on most tasks excepts naming on the BNT, and patient 05, who had high performances before treatment, showed some subtle changes in cognitive measures and in reading. There are two important aspects that likely contribute to the improvements observed. First, therapy was targeted at specific aspects of language and cognitive processing that were deemed to be impaired during the standardized tests. As an example, patient 84 presented with severe language impairments; therapy targeted at copying words of different lengths improved as a function of treatment. This patient also showed notable improvements on the writing subtest of the WAB (which measures copying words/sentences among other things). Likewise, patient 05, who presented with relatively high cognitive and language skills, practiced multiplication among other therapy tasks and demonstrated improvements not only on that task, but also showed improvements on the subtests of the WAB that assessed calculation. Therefore, impairment-based therapy when targeted toward the right language/cognitive skill can be improved, even in seemingly chronic patients.
A second and noteworthy observation was that when participants were encouraged to complete homework practice in addition to their clinic sessions, they appeared to be very diligent and motivated in completing therapy at home. Thus, patient 84 completed 48 therapy sessions, patient 25 completed 73 therapy sessions, and patient 05 completed 89 therapy sessions. $\mathrm{Pa}-$ tient 108 was a control participant (thus he only completed the therapy during his weekly therapy session), but even this individual was very motivated to complete therapy and showed improvements on the standardized tests. Therefore, participant motivation to complete the therapy was likely another factor that facilitated the positive findings in this study. Clearly, a caveat to these results is that all four cases discussed here have shown remarkable improvements. A larger study underway will allow us to systematically examine the amount of improvements as a function of therapy practice.

In the meantime, there are some tentative preliminary conclusions we can draw from this study. There is a huge need to continue longterm therapy for individuals with chronic brain damage; however, insurance limits to therapy reimbursement and physical limitations are huge barriers for these individuals to effectively obtain continued rehabilitation services. Recent technological advances, especially smart tablets and Internet-based applications, provide a unique way to empower these individuals to take control of their rehabilitation, by providing them access to these technologies. The key part of access to tablet- and mobile-based technologies is the collaborative and interactive aspect that allows patients to continue therapy outside the traditional clinical setting, such as at their home, and stay connected with their clinician to manage their rehabilitation program. These advances in technologies have the potential to reshape the way rehabilitation is conducted for individuals who require ongoing communication therapy but struggle to find practical and financially viable options to continue their rehabilitation. As Van de Sandt-Koenderman notes, "The role of the clinician will then shift to one of an advisor and orchestrator of the rehabilitation process. Based on careful diagnostics at all three levels of aphasia rehabilitation, the clinician can choose which treatment 
approach is needed and offer relevant treatment programs that enable the client to work on his or her own rehabilitation, independently and at his or her own pace." ${ }^{5(\text { p. } 26)}$ For researchers in rehabilitation research, the ability to use these emerging technologies provides new and exciting opportunities to examine the effectiveness of different rehabilitation approaches.

\section{REFERENCES}

1. Centers for Disease Control and Prevention. Stroke facts. Available at: http://www.cdc.gov/ stroke/facts.htm. Accessed on December 16, 2013

2. Centers for Disease Control and Prevention. Injury Prevention and Control: Traumatic Brain Injury. Available at: http://www.cdc.gov/traumaticbraininjury/statistics.html. Accessed on December 16, 2013

3. Brennan DM, Georgeadis AC, Baron CR, Barker LM. The effect of videoconference-based telerehabilitation on story retelling performance by brain-injured subjects and its implications for remote speech-language therapy. Telemed J E Health 2004;10(2):147-154

4. Hill AJ, Theodoros DG, Russell TG, Cahill LM, Ward EC, Clark KM. An Internet-based telerehabilitation system for the assessment of motor speech disorders: a pilot study. Am J Speech Lang Pathol 2006;15(1):45-56

5. Goral M, Rosas J, Conner PS, Maul KK, Obler LK. Effects of language proficiency and language of the environment on aphasia therapy in a multilingual. J Neurolinguist 2012;25(6):538-551

6. Goral M, Levy ES, Kastl R. Cross-language treatment generalisation: a case of trilingual aphasia. Aphasiology 2007;103(1-2):203-204

7. van de Sandt-Koenderman WM. Aphasia rehabilitation and the role of computer technology: can we keep up with modern times? Int J Speech-Language Pathol 2011;13(1):21-27

8. Johansson B, Tornmalm M. Working memory training for patients with acquired brain injury: effects in daily life. Scand J Occup Ther 2012;19(2): 176-183

9. Lundqvist A, Grundström K, Samuelsson K, Rönnberg J. Computerized training of working memory in a group of patients suffering from acquired brain injury. Brain Inj 2010;24(10): 1173-1183

10. Barnes DE, Yaffe K, Belfor N, et al. Computerbased cognitive training for mild cognitive impairment: results from a pilot randomized, controlled trial. Alzheimer Dis Assoc Disord 2009; 23(3):205-210
11. Finn M, McDonald S. Computerised cognitive training for older persons with mild cognitive impairment: a pilot study using a randomised controlled trial design. Brain Impair 2011;12(3):187-199

12. Thompson CK, Choy J, Holland A, Cole R. Sentactics: Computer-automated treatment of underlying forms. Aphasiology 2010;24(10):1242-1266

13. Cherney LR. Oral reading for language in aphasia (ORLA): evaluating the efficacy of computer-delivered therapy in chronic nonfluent aphasia. Top Stroke Rehabil 2010;17(6):423-431

14. Kertesz A. The Western Aphasia Battery-Revised. San Antonio, TX: Psych Corp.; 2007

15. Kaplan E, Goodglass H, Weintraub S. Boston Naming Test. 2nd Ed. Philadelphia, PA: Lippincott Williams \& Wilkins; 2001

16. Howard D, Patterson K. Pyramids and Palm Trees. London, England: Harcourt Assessment; 1992

17. Helm-Estabrooks N. Cognitive Linguistic Quick Test. London, England: Harcourt Assessment; 2001

18. Renvall K, Laine M, Martin N. Treatment of anomia with contextual priming: exploration of a modified procedure with additional semantic and phonological tasks. Aphasiology 2007;21(5):499-527

19. Raymer A, Ellsworth TA. Response to contrasting verb retrieval treatments: a case study. Aphasiology 2002;17(3):305-328

20. Doesborgh SJ, van de Sandt-Koenderman MW, Dippel DW, van Harskamp F, Koudstaal PJ, Visch-Brink EG. Effects of semantic treatment on verbal communication and linguistic processing in aphasia after stroke: a randomized controlled trial. Stroke 2004;35(1):141-146

21. Rose M, Douglas J, Matyas T. The comparative effectiveness of gesture and verbal treatments for a specific phonologic naming impairment. Aphasiology 2002;16(10-11):1001-1030

22. Corsten S, Mende M, Cholewa J, Huber W. Treatment of input and output phonology in aphasia: a single case study. Aphasiology 2007; 21(6-8):587-603

23. Franklin S, Buerk F, Howard D. Generalised improvement in speech production for a subject with reproduction conduction aphasia. Aphasiology 2002;16(10-11):1087-1114

24. Tessier C, Weill-Chounlamountry A, Michelot N, Pradat-Diehl P. Rehabilitation of word deafness due to auditory analysis disorder. Brain Inj 2007; 21(11):1165-1174

25. Kendall DL, Rosenbek JC, Heilman KM, et al. Phoneme-based rehabilitation of anomia in aphasia. Brain Lang 2008;105(1):1-17

26. Drew RL, Thompson CK. Model-based semantic treatment for naming deficits in aphasia. J Speech Lang Hear Res 1999;42(4):972-989

27. Kiran S, Thompson CK. The role of semantic complexity in treatment of naming deficits: training semantic categories in fluent aphasia by controlling 
exemplar typicality. J Speech Lang Hear Res 2003; 46(3):608-622

28. Kiran S, Sandberg C, Sebastian R. Treatment of category generation and retrieval in aphasia: effect of typicality of category items. J Speech Lang Hear Res 2011;54(4):1101-1117

29. Morelli CA, Altmann LJP, Kendall D, Fischler I, Heilman KM. Effects of semantic elaboration and typicality on picture naming in $\mathrm{Al}$ zheimer disease. J Commun Disord 2011;44(4):413-428

30. Hashimoto N, Frome A. The use of a modified semantic features analysis approach in aphasia. J Commun Disord 2011;44(4):459-469

31. Rose M, Douglas J. Treating a semantic word production deficit in aphasia with verbal and gesture methods. Aphasiology 2008;22(1):20-41

32. Stanczak L, Waters G, Caplan D. Typicality-based learning and generalisation in aphasia: two case studies of anomia treatment. Aphasiology 2006; 20(2-4):374-383

33. Rochon E, Leonard C, Burianova H, et al. Neural changes after phonological treatment for anomia: an fMRI study. Brain Lang 2010;114(3):164-179

34. Lorenz A, Ziegler W. Semantic vs. word-form specific techniques in anomia treatment: a multiple single-case study. J Neurolinguist 2009;22(6): 515-537

35. Wambaugh JL. A comparison of the relative effects of phonologic and semantic cueing treatments. Aphasiology 2003;17(5):433-441

36. Annoni JM, Khateb A, Custodi MC, Debeauvais V, Michel CM, Landis T. Advantage of semantic language therapy in chronic aphasia: a study of three cases. Aphasiology 1998;12(12):1093-1105

37. Kiran S, Sandberg C, Sebastian R. Treatment of category generation and retrieval in aphasia: effect of typicality of category items. J Speech Lang Hear Res 2011;54(4):1101-1117

38. Katz RC, Wertz RT. The efficacy of computerprovided reading treatment for chronic aphasic adults. J Speech Lang Hear Res 1997;40(3): 493-507

39. Lacey EH, Lott SN, Snider SF, Sperling A, Friedman RB. Multiple oral re-reading treatment for alexia: the parts may be greater than the whole. Neuropsychol Rehabil 2010;20(4):601-623

40. Sinotte MP, Coelho CA. Attention training for reading impairment in mild aphasia: a follow-up study. NeuroRehabilitation 2007;22(4):303-310

41. Cherney LR, Merbitz CT, Grip JC. Efficacy of oral reading in aphasia treatment outcome. Rehabil Lit 1986;47(5-6):112-118

42. Beeson PM, Hirsch FM, Rewega MA. Successful single-word writing treatment: experimental analyses of four cases. Aphasiology 2002;16(4):473-491

43. Beeson PM, Egnor H. Combining treatment for written and spoken naming. J Int Neuropsychol Soc 2006;12(6):816-827
44. Beeson PM, Rising K, Kim ES, Rapcsak SZ. A novel method for examining response to spelling treatment. Aphasiology 2008;22(7-8):707-717

45. Ball AL, de Riesthal M, Breeding VE, Mendoza DE. Modified ACT and CART in severe aphasia. Aphasiology 2011;25(6-7):836-848

46. Wright HH, Marshall RC, Wilson KB, Page JL. Using a written cueing hierarchy to improve verbal naming in aphasia. Aphasiology 2003;17(8): 767-780

47. Robson J, Marshall J, Chiat S, Pring T. Enhancing communication in jargon aphasia: a small group study of writing therapy. Int J Lang Commun Disord 2001;36(4):471-488

48. Schechter I, Bar-Israel J, Ben-Nun Y, Bergman M. The phonemic analysis as a treatment method in dysgraphic aphasic patients. Scand J Rehabil Med Suppl 1985;12:80-83

49. Kiran S. Training phoneme to grapheme conversion for patients with written and oral production deficits: a model-based approach. Aphasiology 2005;19(1):53-76

50. Rapp B. The relationship between treatment outcomes and the underlying cognitive deficit: evidence from the remediation of acquired dysgraphia. Aphasiology 2005;19:994-1008

51. Kiran S, Viswanathan M. Effect of model-based treatment on oral reading abilities in severe alexia: a case study. J Med Speech-Lang Pathol 2008; 16(1):43

52. Weinrich M, Boser KI, McCall D. Representation of linguistic rules in the brain: evidence from training an aphasic patient to produce past tense verb morphology. Brain Lang 1999;70(1): $144-158$

53. Kiran S, Thompson CK, Hashimoto N. Training grapheme to phoneme conversion in patients with oral reading and naming deficits: a model-based approach. Aphasiology 2001;15:855-876

54. Salis C, Edwards S. Treatment of written verb and written sentence production in an individual with aphasia: a clinical study. Aphasiology 2010;24(9): 1051-1063

55. Rochon E, Reichman S. A modular treatment for sentence processing impairments in aphasia: sentence production. J Speech Lang Pathol Audiol 2003;27(4):202-210

56. Stadie N, Schröder A, Postler J, et al. Unambiguous generalization effects after treatment of non-canonical sentence production in German agrammatism. Brain Lang 2008;104(3):211-229

57. Weinrich M, Boser KI, McCall D, Bishop V. Training agrammatic subjects on passive sentences: implications for syntactic deficit theories. Brain Lang 2001;76(1):45-61

58. Park NW, Ingles JL. Effectiveness of attention rehabilitation after an acquired brain injury: a metaanalysis. Neuropsychology 2001;15(2):199-210 
59. Sohlberg MM, Mateer CA. Effectiveness of an attention-training program. J Clin Exp Neuropsychol 1987;9(2):117-130

60. Berryman A, Rasavage K, Politzer T. Practical clinical treatment strategies for evaluation and treatment of visual field loss and visual inattention. NeuroRehabilitation 2010;27(3):261-268

61. Funk J, Finke K, Reinhart S, et al. Effects of feedback-based visual line-orientation discrimination training for visuospatial disorders after stroke. Neurorehabil Neural Repair 2013;27(2):142-152

62. McGilton KS, Rivera TM, Dawson P. Can we help persons with dementia find their way in a new environment? Aging Ment Health 2003;7(5): 363-371

63. Brunsdon R, Nickels L, Coltheart M, Joy P. Assessment and treatment of childhood topographical disorientation: a case study. Neuropsychol Rehabil 2007;17(1):53-94

64. Klingberg T, Forssberg H, Westerberg H. Training of working memory in children with ADHD.J Clin Exp Neuropsychol 2002;24(6):781-791

65. Klingberg T. Training and plasticity of working memory. Trends Cogn Sci 2010;14(7):317-324

66. Westerberg H, Jacobaeus H, Hirvikoski T, et al. Computerized working memory training after stroke-a pilot study. Brain Inj 2007;21(1):21-29

67. Hart T, Hawkey K, Whyte J. Use of a portable voice organizer to remember therapy goals in traumatic brain injury rehabilitation: a withinsubjects trial. J Head Trauma Rehabil 2002; 17(6):556-570

68. Eriksen CW. The flankers task and response competition: a useful tool for investigating a variety of cognitive problems. Vis Cogn 1995;2(2-3): 101-118

69. Vallat C, Azouvi P, Hardisson H, Meffert R, Tessier C, Pradat-Diehl P. Rehabilitation of verbal working memory after left hemisphere stroke. Brain Inj 2005;19(13):1157-1164

70. Vallat-Azouvi C, Pradat-Diehl P, Azouvi P. Rehabilitation of the central executive of working memory after severe traumatic brain injury: two single-case studies. Brain Inj 2009;23(6):585-594

71. Martin RC, Triebel K, Dreer LE, Novack TA, Turner C, Marson DC. Neurocognitive predictors of financial capacity in traumatic brain injury. J Head Trauma Rehabil 2012;27(6):E81-E90

72. Whetstone $\mathrm{T}$. The representation of arithmetic facts in memory: results from retraining a braindamaged patient. Brain Cogn 1998;36(3):290-309

73. Basso A, Cattaneo S, Girelli L, et al. Treatment efficacy of language and calculation disorders and speech apraxia: a review of the literature. Eur J Phys Rehabil Med 2011;47(1):101-121

74. Domahs F. Bar tha L, Delazer M. Rehabilitation of arithmetic abilities: different intervention strategies for multiplication. Brain Lang 2003;87: 165-166

75. Girelli L, Delazer M, Semenza C, Denes G. The representation of arithmetical facts: evidence from two rehabilitation studies. Cortex 1996;32(1): 49-66

76. Ehlhardt LA, Sohlberg MM, Glang A, Albin R. TEACH-M: a pilot study evaluating an instructional sequence for persons with impaired memory and executive functions. Brain Inj 2005;19(8): 569-583

\begin{tabular}{|c|c|}
\hline Therapy Type & Cognitive/Language Operation and Supporting Evidence \\
\hline \multicolumn{2}{|l|}{ Naming Therapy } \\
\hline Rhyme judgment & Retraining phonological encoding and processing ${ }^{18-20}$ \\
\hline Syllable identification & Retraining phonological segmentation ${ }^{21}$ \\
\hline Sound identification & Retraining phonological processing $22-24$ \\
\hline Category matching & Semantic categorization to strengthen semantic boundaries ${ }^{26-28}$ \\
\hline Feature matching & $\begin{array}{l}\text { Analysis of semantic features to strengthen semantic } \\
\text { representations }{ }^{12,13,29-32}\end{array}$ \\
\hline Picture naming & Retrieving semantic-phonological representations of words $s^{7,33-35}$ \\
\hline \multicolumn{2}{|l|}{ Reading therapy } \\
\hline $\begin{array}{l}\text { Spoken word-written } \\
\text { identification }\end{array}$ & Auditory word recognition ${ }^{36}$ \\
\hline $\begin{array}{l}\text { Written word category } \\
\text { identification }\end{array}$ & $\begin{array}{l}\text { Word semantic relatedness judgment to strengthen semantic } \\
\text { associations }^{37}\end{array}$ \\
\hline Reading passages & Retraining sentence and story comprehension $38-41$ \\
\hline
\end{tabular}


Appendix 1 (Continued)

\begin{tabular}{|c|c|}
\hline Therapy Type & Cognitive/Language Operation and Supporting Evidence \\
\hline $\begin{array}{l}\text { Long passage reading } \\
\text { comprehension }\end{array}$ & Retraining sentence and story comprehension with longer passages ${ }^{26}$ \\
\hline \multicolumn{2}{|l|}{ Writing therapy } \\
\hline Word copy completion & Retraining orthographic representations ${ }^{42-47}$ \\
\hline Word copy & $\begin{array}{l}\text { Retraining orthographic representations with some letters provided- } \\
\text { same as word copy }\end{array}$ \\
\hline Word spelling completion & $\begin{array}{l}\text { Retraining orthography using phoneme-to-grapheme conversion with } \\
\text { some letters provided }{ }^{29,48,49}\end{array}$ \\
\hline Word spelling & $\begin{array}{l}\text { Retraining orthographic access and phoneme-to-grapheme conversion- } \\
\text { same as word spelling completion }\end{array}$ \\
\hline Picture spelling completion & $\begin{array}{l}\text { Retraining orthographic access and phoneme-to-grapheme conversion } \\
\text { with some letters provided } 50\end{array}$ \\
\hline Picture spelling & $\begin{array}{l}\text { Retraining orthographic access and phoneme-to-grapheme conversion } \\
\text { with some letters provided }\end{array}$ \\
\hline Sound-to-letter matching & Retraining phoneme-to-grapheme conversion skills $31,51,52$ \\
\hline Letter-to-sound matching & Retraining grapheme-to-phoneme conversion skills ${ }^{34,53}$ \\
\hline \multicolumn{2}{|l|}{ Sentence planning } \\
\hline $\begin{array}{l}\text { Active and passive sentence } \\
\text { completion }\end{array}$ & $\begin{array}{l}\text { Retraining simple sentence construction using active and passive } \\
\text { sentences }{ }^{54-57}\end{array}$ \\
\hline \multicolumn{2}{|l|}{ Visuospatial processing } \\
\hline Symbol cancellation & Retraining visuospatial scanning, attention to visual stimuli ${ }^{58-60}$ \\
\hline Telling time/analog clock & Retraining strengthening of visuospatial information such as clock ${ }^{71}$ \\
\hline Reading maps & Retraining strengthening visuospatial organization and analytical skills ${ }^{62,63}$ \\
\hline \multicolumn{2}{|l|}{ Memory } \\
\hline $\begin{array}{l}\text { Visuospatial picture/written } \\
\text { word/spoken matching }\end{array}$ & $\begin{array}{l}\text { Incrementally retraining visuospatial working memory for picture, written } \\
\text { word or spoken stimuli64-66 }\end{array}$ \\
\hline Voicemail task & Retraining auditory working memory using a functional task ${ }^{51,67}$ \\
\hline \multicolumn{2}{|l|}{ Attention } \\
\hline Response inhibition & Retraining sustained attention and response inhibition ${ }^{68}$ \\
\hline Symbol cancellation & Retraining visuospatial scanning, attention to visual stimuli ${ }^{43-45}$ \\
\hline \multicolumn{2}{|l|}{ Problem solving } \\
\hline $\begin{array}{l}\text { Alphabetical word/picture } \\
\text { ordering }\end{array}$ & $\begin{array}{l}\text { Retraining verbal working memory and analytical reasoning skills to sort } \\
\text { words/pictures alphabetically }{ }^{69}\end{array}$ \\
\hline $\begin{array}{l}\text { Arithmetic tasks (addition, } \\
\text { subtraction, etc.) }\end{array}$ & $\begin{array}{l}\text { Strengthening non-linguistic cognitive processing and working } \\
\text { memory }\end{array}$ \\
\hline \multicolumn{2}{|l|}{ Quantitative reasoning } \\
\hline Word problem & Verbal and analytical reasoning to complete mathematical solutions \\
\hline \multicolumn{2}{|l|}{ Executive function } \\
\hline Instruction sequencing & $\begin{array}{l}\text { Strengthening goal directed planning and organization for functional } \\
\text { information }{ }^{76}\end{array}$ \\
\hline
\end{tabular}

